\title{
CF-reduplication in English: Dynamic Prototypes \& Contrastive Focus Effects
}

\author{
Myounghyoun Song \\ Seoul National University
}

\author{
Chungmin Lee \\ Seoul National University
}

\begin{abstract}
This paper puts forward a category-based account of CF-reduplications by means of a prototype category, dynamic prototpypes and contrastive focus effects. The CF-reduplications refer to three different levels of a category: the prototype of a category, the subcategories in a category or a category itself. The CF-marked modifier receives the intension of a base word and produces a contingently determined denotation of CF-reduplications, on the basis of dynamic prototypes in the minds of speakers. The Contrastive Focus exhaustively selects the denotation of the CFreduplications out of immediately relevant alternatives in the discourse. CFreduplications semantically have dynamically changing denotations and pragmatically facilitate the communication between speakers with contrastive focus effects.
\end{abstract}

Keywords: Contrastive Focus, Dynamic Prototypes, Relevant Alternatives, Intensional Semantics

\section{Introduction}

The Contrastive Focus Reduplication ${ }^{1}$ (henceforth, CF-reduplication; cf. Double Construction in Dray 1987, Lexical Cloning in Horn 1993) has been viewed as a phenomenon of colloquial English, denoting the prototypical instance of the reduplicated expression or singling out a member or subset ... that represents a true, real, default, or a prototypical instance, as illustrated in (1).

(1) a. No, what I wanted was a $\operatorname{dog}_{\mathrm{CF}}-\mathrm{dog}$. (Horn 1993: 48)

b. I'll make the tuna salad, and you make the salad CF $_{\text {-salad. }}$

(Ghomeshi et a1. 2004: 308)

c. Did you go to the movie with Dave or with Dave $\mathrm{CF}_{\mathrm{C}}$-Dave? (ib.: 314 )

\footnotetext{
1 This paper is based on Myounghyoun Song, Chungmin Lee's SICOL (2010) paper. We thank Dongsik Lim for relevant discussions, Wes Holliday and SALT 21 reviewers for helpful comments. The term 'Contrastive Focus Reduplication' comes from Ghomeshi et al. (2004) in their sense that the reduplicated element is copied from the base and obtains a contrastive focus accent to trigger a set of alternatives in the common ground between the speaker and the hearer. Part of this work was supported by KRF-2009-342A00017 (Excellent Scholar Project) granted to Chungmin Lee.
} 
We agree that the CF-reduplicated forms ${ }^{2}$ in (1) express the prototypical instance of a property or an individual concept in such a way that ' $\operatorname{dog}_{\mathrm{CF}}-\mathrm{dog}$ ' in (a) denotes a German shepherd (or a collie), 'salad ${ }_{\mathrm{CF}}$-salad' does a 'green salad' in (b) and 'Dave ${ }_{\mathrm{CF}}$-Dave' does the close and familiar individual called Dave in (c), respectively. We also agree with Whitton 2006 that CF-reduplications cannot be understood satisfactorily without considering many possible denotations involving them, as shown in (2) (Whitton 2006: 19-21).

(2) a. You said in an earlier article that if you must have a "drink drink" go with the hard liquor. Why is hard liquor better than beer?

b. "Do you want a bottle of wine?" Mac asks. "I think I'll have a drinkdrink," I say and when the waiter comes I order a martini.

c. (around 3 euros a shot and 8 euros a drink-drink).

d. [Two people at fast food restaurant sharing a meal deal]

A: What do you want?

B: I'll probably just get water so if you want a drink-drink get whatever you want.

e. A: I am on my own with the BBQ! Come on girls I need some drink ideas. Please- Celeste.

B: Are you looking for alcohol? Or just a drink-drink.

Whitton 2006 rejected the prototype of a category as the meaning of CFreduplications and proposed a scalar analysis in which a context provides a large number of dimensions on which to order possible alternatives to construct a contrast set for each CF-reduplication. The contrast sets for the drink-drinks in (2) are $\left.\{\text { (alcoholic drink, } \sim \text { nonalcoholic drink })^{3}\right\}$ in (a), \{(martini, $\sim$ wine $\left.)\right\}$ in (b), $\{($ mixed drink in a glass, $\sim$ shot $)\}$ in $(\mathrm{c}),\{($ soda, $\sim$ water $)\}$ in $(\mathrm{d})$, and $\{($ nonalcoholic drink, $\sim$ alcoholic drink) $\}$ in (e), respectively.

The scalar approach, however, tends to work in a limited way. First, it can't interpret CF-reduplications without constructing a contrast set from the context. In fact, English native speakers have no difficulty in accessing the interpretation of CF-reduplications without the help of a context so that they can process the meaning of a ' $\operatorname{dog}_{\mathrm{CF}}$-dog' in (1a) as 'big, scruffy, and independent' dog like 'a German shepherd', a 'salad ${ }_{\mathrm{CF}}$-salad' in (1b) as 'a salad based on lettuce' like 'green salad'. They usually take a 'drink $\mathbf{C F}_{\mathrm{CF}}$-drink' as meaning 'an alcoholic drink'

2 Lee (2003) marks the contrastive focused element with the subscripted capital ${ }_{\mathrm{CF}}$, as below.

\{Sam drove Mary's red convertible. What did he drive before that?\}

A: He drove her blue ${ }_{\mathrm{CF}}$ convertible.

In this paper, we follow this notation to mark the Contrastive Focus on the CF-marked modifier.

3 Whitton (2006) marked $\sim$ before the second item in the contrast set to indicate that it is rejected by the speaker. 
or 'a strong alcoholic drink' like 'vodka' and a 'sleeping together ${ }_{\mathrm{CF}}$-sleeping together' as 'sexual intercourse'. Even without a particular context, CFreduplications have their own denotation(s) based on the common beliefs of the speech community in default contexts, which enables us to analyze the semantics of the phenomenon. Second, the dimensions are ad hoc and weak. The dimensions will continue to be introduced as situations demand. The drink-drinks in (2), for example, have already created 4 dimensions: alcoholicity, alcohol by volume, container and carbonation. They will increase in number as situations change. Also, some dimensions allow the elements in the contrast set $\{$ (soda, $\sim$ water) $\}$ to be reversed like $\{($ water, $\sim$ soda $)\}$ while other dimensions disallow the reversal between the elements in the contrast set, like $\{$ (martini, $\sim$ wine $)\}$ and $*\{$ (wine, $\sim$ martini) $\}$, which invites explanation. Lastly, it does not provide a uniform criterion for the strength of the construals. The intended construal 'martini' is stronger than 'beer' in the contrast set $\{$ (martini, $\sim$ beer $)\}$ for the 'drink $\mathbf{k}_{\mathrm{CF}}$-drink' as in "I don't want a beer. I want a drink $\mathbf{C F}_{\mathrm{CF}}$-drink", since the former is stronger in alcohol per volume than the latter. The intended construal 'green salad' is, on the other hand, stronger than 'Caesar salad' in the contrast set (green salad, Caesar salad) $\}$ as in "Last time I made a Caesar salad. This time I will make a salad CF- $^{-}$ salad", even though the former seems to have less ingredients than the latter. All the limitations above stem from the absence of the concept of a prototype category. With a prototype for CF-reduplications, native English speakers would have no problem in accessing interpretations of CF-reduplications without a particular context, in selecting a prototype of a category or a prototype among other relevant types of a category without any dimensions.

We thus propose that CF-reduplications refer to each of the three different levels of a category: the prototype of a category, as in (3a), subcategories in a category, as in (3b), and a category itself, as in (3c).

(3) a. (i) Mary: Would you like a wine? Jason: No, a drink $\mathbf{C F}_{\mathrm{CF}}$-drink. I'll have some vodka.

(ii) Mary: Would you like a coke? Jason: No, a drink $\mathrm{CF}_{\mathrm{CF}}$-drink. I'll have some water.

b. (i) (Jason, the husband, comes back after lots of work from his garden, with sweat pouring down his face. Mary, the wife, meets him at home.)

Jason: I want a drink.

Mary: Here, have some beer.

Jason: No, I want a drink $\mathbf{C F}_{\mathrm{C}}$-drink. With no alcohol.

(ii) (Jason, the husband, spends Sunday afternoon sleeping and relaxing. Mary, the wife, comes back from a mall.)

Jason: I want a drink.

Mary: Here, have some water.

Jason: No, I want a drink $\mathbf{C F}_{\mathrm{CF}}$-drink. With alcohol. 
c. (Two attractive models are auditioning for a magazine at a photo shoot. Jason holds sunglasses and a bottle of sunscreen while Mary holds a fan and a plastic replica of a glass of lemonade.)

Jason: It's really hot in here. I'd love a drink right now.

Mary: (handing him the lemonade prop) Here!

Jason: No, a drink $\mathbf{C F}_{\mathrm{CF}}$-drink, silly!

The 'drink $\mathbf{C F F}_{\mathrm{CF}}$-drink' in (3ai) refers to the prototype of an alcoholic drink subcategory which is best matched by the exemplar 'vodka' while the one in (3aii) refers to the prototype of a nonalcoholic drink subcategory whose best example is 'water'. Meanwhile, the 'drink $\mathbf{C F}_{\mathrm{C}}$-drink' in (3b) refers to either of the subcategories of a drink category, 'alcoholic drink' in (i) or 'nonalcoholic drink' in (ii). Lastly, the 'drink $\mathbf{C}_{\mathrm{CF}}$-drink' in (3c) refers to the category of a drink. Here, the concept of a prototype is not static but dynamic to reflect the contingently determined denotations of CF-reduplications as further witnessed in (4).

(4) a. No more comic books. Read $\mathbf{b o o k}_{\mathrm{CF}}$-books for the exams.

b. No more school textbooks. Do what the book $_{\mathrm{CF}}$-books say.

c. No more novels. Read book $_{\mathrm{CF}}$-books in church.

The denotations of CF-reduplication in (4) co-vary as the contexts vary. The denotations of ' book $_{\mathrm{CF}}$-books' vary from 'textbooks' in an exam-preparation context, as in (a), to 'cookbooks' in a cooking contest context, as in (b), and to 'the Bible' in a church context, as in (c). The dynamic prototypes will cover various cases of CF-reduplications that have contingently determined denotations.

This study aims to provide a category-based account of CF-reduplications by means of a prototype category, dynamic prototypes and contrastive focus effects. In 2.1, we revisit the concept of a prototype and present dynamic prototypes to account for the contingently determined denotations of CF-reduplications. In 2.2, we go on to deal with CF-reduplications which refer to two different subcategories in a category (polysemous CF-reduplications). In 2.3, we deal with the ones that refer to a category itself (categorical CF-reduplications), and the ones that refer to two separate categories in a lexical concept (homonymous CFreduplications). Lastly, in 3, we try to formalize denotations of CF-reduplications. Section 4 concludes the study. 


\section{Category-based Interpretations of CF-reduplications}

\subsection{CF-reduplications referring to the prototype of a category}

When native English speakers use a CF-reduplicated expression, they tend to think of it as referring to the prototype of a category, as in (5).

(5) I'll make the chicken salad, and you make the salad $_{\mathrm{CF}}$-salad.

A prototype is "a schematic representation of the conceptual core of a category" (Taylor 1989). The conceptual core consists of essential attributes and their values that are determined against their common ground between speakers. The conceptual core of a 'salad' is, for example, schematically represented with an attribute-value matrix, as in (6).

(6) Conceptual Core of a 'salad'

$\left[\begin{array}{ll}\text { INGREDIENT } & x \\ \text { DRESSING } & y\end{array}\right]$

The matrix in (6) is characterized by the essential attributes such as 'INGREDIENT' and 'DRESSING', leading to many different relevant alternatives by the assignment of a value to each variable, as in (7). Here the relevant alternatives share the same essential attributes to belong to a category and should be immediately available in the context where speakers participate.

(7) Relevant Alternatives of 'salad'
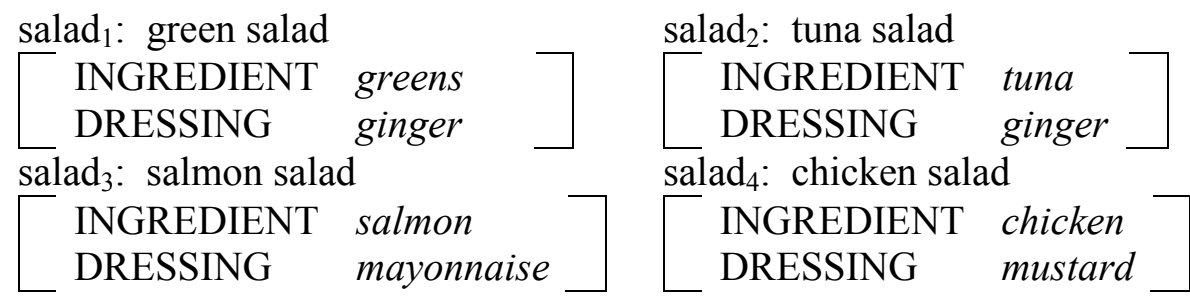

Most native speakers have a 'salad with green ingredients tossed with a ginger dressing' as a conceptual core in their minds and they match a 'green salad' among relevant alternatives with the prototype, as indicated by its position in the center of the concentric circles in Figure 1. The salad $_{\mathrm{CF}}$-Salad in (5) comes to denote the best example of the prototype of a salad category, i.e. green salad. 


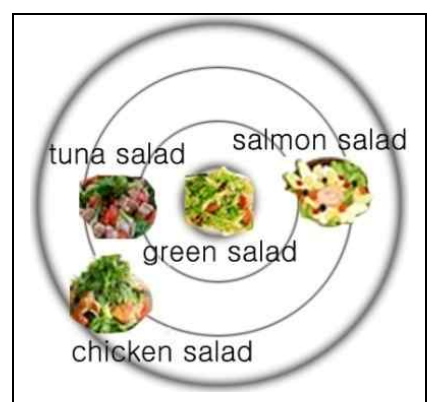

Figure 1 Prototype Structure of a 'salad' Category

However, there is not the one and only prototype for each category. Speakers conceptualize a prototype category in a correspondingly different way in a different situation. In fact, native English speakers ${ }^{4}$ in a survey responded with many different prototypes for each category, as shown in Table 1.

\begin{tabular}{|l|l|l|}
\hline \multicolumn{3}{|c|}{ Categories } \\
\hline \multicolumn{1}{|c|}{ salad } & \multicolumn{1}{|c|}{ bird } & \multicolumn{1}{|c|}{ book } \\
\hline $\begin{array}{l}\text { green salad (9), Caesar } \\
\text { salad (7), chicken salad }\end{array}$ & $\begin{array}{l}\text { eagle (9), robin (3), pigeon (2), } \\
\text { cardinal (2), oriole (1), sparrow (1), }\end{array}$ & $\begin{array}{l}\text { novel (18), Bible (4) } \\
\text { nonfiction (2), text (1) }\end{array}$ \\
$\begin{array}{l}\text { 3), tomato salad (1), } \\
\text { maldorf salad (2), cobb } \\
\text { salad (2), chef salad (1) }\end{array}$ & $\begin{array}{l}\text { (1), hamming bird (1), parrot } \\
\text { wood pecker (1), kiwi (1) }\end{array}$ & \\
\hline
\end{tabular}

\section{Table 1 Prototypes of Categories}

Table 1 shows that there exists a major prototype among many prototypes, like 'green salad' for a salad category, 'eagles' for a bird category, and 'novel' for a book category. Even though those major prototypes are construed as denotations of CF-reduplications, other minor prototypes are accepted as possible denotations like the ' book $_{\mathrm{CF}}$-books' in (8).

(8) a. No more comic books. Read book $_{\mathrm{CF}}$-books for the exams.

b. No more school textbooks. Do what the book $_{\mathrm{CF}}$-books say.

c. No more novels. Read book $_{\mathrm{CF}}$-books in church.

425 native speakers (18 Americans, 4 Canadians, 2 British, 1 New Zealander) participated in a survey conducted in a gathering in Seoul, Korea in June, 2011.

5 The predominent choice of 'eagle' for bird $\mathbf{C F}_{\mathrm{CF}}$-bird (or a German shepard' for $\mathbf{d o g}_{\mathrm{CF}}$-dog) shows that speakers prefer to denote a salient type to the common (familiar) prototype such as a robin. Ordinarily, Americans and Canadians refer to 'a robin' particularly when they are asked a question, "What's the prototype of a bird?" However, speakers tend to choose 'greean salad' for

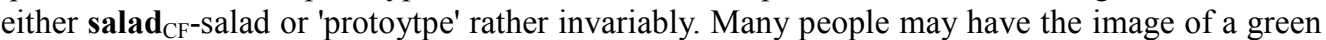
salad as prototypical and as salient as well (although they may go to a Ceasar salad for the reduplication.) 
The 'book $\mathbf{C F}_{\mathrm{CF}}$-books' in (8) denotes 'textbooks' in a context where the hearer is expected to prepare for upcoming exams in (a), 'cookbooks' in a context where the hearer is expected to compete for a cooking contest in (b) or 'the Bible' in a context where the speakers are in a church in (c). The uses of the CFreduplication 'book $\mathbf{k}_{\mathrm{CF}}$-books' activate three different prototype structures in the speakers' minds, as in Figure 2.

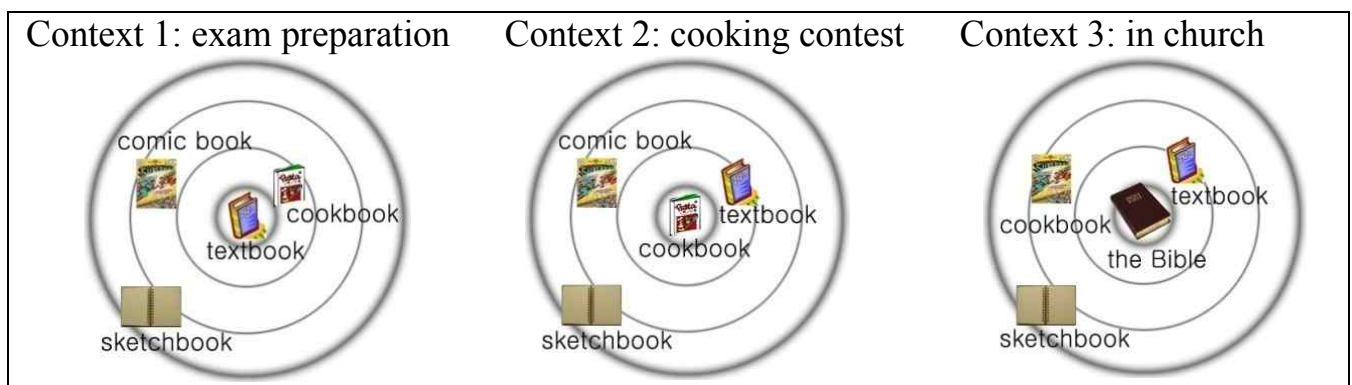

Figure 2 Prototype Structures of a ‘book' Category

In Figure 2, there are three prototypes differently embodied by the salient exemplars in three situations as denotations of the CF-reduplication. The 'textbook' in 'exam preparation context' best matches the prototype, that is, 'textprinted school book with a paperback cover bound by perfect binding'. Similarly, the 'cookbook' is in the center of the concentric circles, matching the prototype of a book, i.e., 'recipe-printed book with a paperback cover bound by perfect binding' in context 2 , and 'the Bible' does so in context 3 . This means that the prototypes of a book category covary as the contexts vary. Dynamic prototypes are a key to interpreting the CF-reduplications that have varying denotations according to contexts. The 'salad ${ }_{\mathrm{CF}}$-salad' usually denotes a 'green salad' but it can denote different salads against different cultural backgrounds since a certain salad is learned and shared by intra-cultural members as a prototype. Thus, it can denote an Israeli salad, which has diced tomatoes and cucumbers among Americans of Jewish extraction. It can also be a Russian salad, which mixes diced potatoes and vegetables among Russian-Americans.

Meanwhile, the contrastive focus accent $\left(\mathrm{H}^{*}\right)$ on CF-reduplications implies that there are immediately relevant alternatives available in the previous discourse, making up an alternative question. According to Lee 2003, "If a concern is phrased as a disjunction, i.e., as in an alternative disjunctive question, and the speaker responds to a single disjunct (as would normally be expected), then the answer is characterized by CF." Looking back on the CF-reduplications in this section, the contrastive focus makes an alternative question with the relevant alternatives that are immediately available from the context, as shown in the curly brackets in (9). 
(9) a. \{Do we make a chicken salad or a green salad?\}

I'll make the chicken salad, and you make the salad $_{\mathrm{CF}}$-salad.

b. (i) \{Can I read comic books or textbooks?\}

No more comic books. Read $\mathbf{b o o k}_{\mathrm{CF}}$-books for the exams.

(ii) \{Can I read school textbooks or cookbooks?\}

No more school textbooks. Do what the book $_{\mathrm{CF}}$-books say.

(iii) $\{$ Can I read novels or the Bible?

No more novels. Read book $_{\mathrm{CF}}$-books in church.

The contrastive foci in (9) semantically function to exclusively select one of the immediately relevant alternatives given in the context. The CF on the salad $\mathrm{CF}^{-}$ salad in (a) selects 'green salad' as the salad that matches the prototype, producing the exclusive implication that the hearer will have to make no other salad than 'green salad'. Also, the CFs on the book $_{\mathrm{CF}}$-books in (b) select the books that match the prototype of a book category in each context with an exclusion of comic books in (i), textbooks in (ii) and novels in (iii). After all, the contrastive focus on CF-reduplications has the hearer pay attention to the immediately relevant alternatives in the previous discourse as a common ground and easily select one of them in terms of prototypicality, which facilitates the communication between the speakers.

\subsection{CF-reduplications referring to the subcategories of a category}

In contrast to the CF-reduplications referring to the prototype of a category, some CF-reduplications refer to the subcategories in a category, which can be termed 'Polysemous CF-reduplications'. A drink $\mathbf{C}_{\mathrm{CF}}$-drink, for example, denotes either of the subcategories, 'an alcoholic drink' and 'a nonalcoholic drink', as in (10).

a. (Jason, the husband, spends Sunday afternoon sleeping and relaxing. Mary, the wife, comes back from a mall.)

Jason: I want a drink.

Mary: Here, have some coke.

Jason: No, I want a drink $\mathbf{k}_{\mathrm{CF}}$-drink. With alcohol.

b. (Jason, the husband, comes back after lots of work from his garden, with sweat pouring down his face. Mary, the wife, meets him at home.)

Jason: I want a drink.

Mary: Here, have some beer.

Jason: No, I want a drink $k_{\mathrm{CF}}$-drink. With no alcohol. 
The 'drink $\mathbf{C F}_{\mathrm{CF}}$-drink' in (10a) refers to the 'alcoholic drink' while the one in (10b) refers to the 'nonalcoholic drink' subcategory in a drink category. The complementary attribute 'alcoholicity' divides a category into two subcategories, one of which has the elements with a positive value (+ alcohol), the other of which has those with a negative value (- alcohol), as shown in Figure 3.

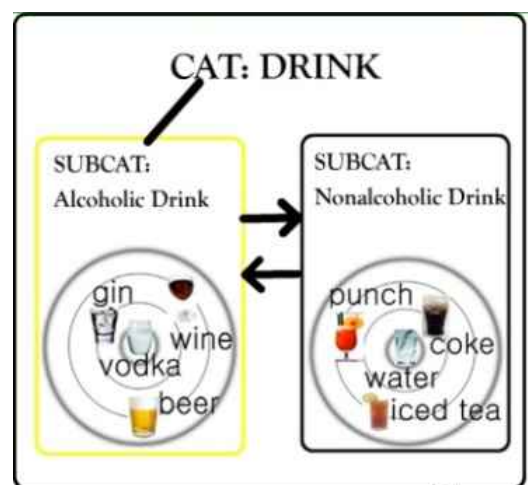

Figure 3 Prototype Structure of a 'drink' Category

In Figure 3, there are two subcategories, alcoholic drink and non-alcoholic drink, in the drink category. Either of them can be understood by the speakers as a denotation of the 'drink $\mathbf{k}_{\mathrm{CF}}$-drink' in the context where it matters whether the drink contains alcohol or not. The solid line from the drink category to the 'alcoholic drink' subcategory indicates that the subcategory is a denotation of the CFreduplication by default (cf. Harel 1987). A default subcategory is the subcategory that overpowers the other subcategory in frequency of uses and conceptual strength in the mind of the speakers. ${ }^{6}$ English native speakers are highly likely to view the 'alcoholic drink' subcategory as a default subcategory rather than the 'nonalcoholic drink'. Thus, they understand the 'drink $\mathbf{C}_{\mathrm{CF}}$-drink' as denoting an 'alcoholic drink' by default.

In the meantime, the contrastive focus serves to disambiguate the CFreduplications referring to the subcategories of a category. ${ }^{7}$ With two distinguished subcategories given in the context, it is understood to make an alternative question in the previous discourse. The bidirectional arrows between

6 Lexicographically, such default subcategory meanings are listed in the dictionary, whereas 'strong alcoholic drink' is not.

7 The relation between a category and its subcategories corresponds to a join operation in a join semi-lattice, as shown below.

A: Did Yumi give birth to a child? \{Did she give birth to a son or a daughter?\}

$\mathrm{B}$ : Ya, she gave birth to a daughter ${ }_{\mathrm{CF}}$.

Here, 'child' constitutes a local top type in a join semi-lattice with 'daughter' and 'son' as lower type elements (Lee 2003: 10), making an alternative question in the previous discourse. 
the two subcategories in Figure 3 indicate that the subcategories can be transitioned dynamically, depending on the presence of a complementary disjunct in the previous discourse. Returning to the examples in (10), the contrastive focus makes an alternative question with two disjuncts of subcategories, as in (11).

a. $\quad\{$ Can I have an alcoholic drink or a nonalcoholic drink?\} Mary: Here, have some coke.

Jason: No, I want a drink $\mathbf{k}_{\mathrm{CF}}$-drink. With alcohol.

b. $\quad$ Can I have an alcoholic drink or a nonalcoholic drink?\} Mary: Here, have some beer.

Jason: No, I want a drink $\mathbf{C F}_{\mathrm{CF}}$-drink. With no alcohol.

The 'drink $\mathbf{C F}_{\mathrm{CF}}$-drink' in (11a) is associated with the 'alcoholic drink', with the exclusion of the other subcategory. The same is true of the 'drink $\mathbf{C F F}_{\mathrm{CF}}$-drink' in (11b), producing a different denotation, a 'nonalcoholic drink'.

\subsection{CF-reduplications referring to a category}

Unlike the CF-reduplications which refer to the inside of a category, some CFreduplications refer to a category itself, as illustrated in (12).
a. (Two attractive models are auditioning for a magazine at a photo shoot. During the audition, they are asked to hold a variety of props while posing for photographs. Jason holds sunglasses and a bottle of sunscreen while Mary holds a fan and a plastic replica of a glass of lemonade.) Jason: It's really hot in here. I'd love a drink right now. Mary: (handing him the lemonade prop) Here!. Jason: No. A drink ${ }_{\mathrm{CF}}$-drink, silly!

b. (A boy high school is converted into a co-educational high school. Some girls show up for the entrance ceremony on the first day of school.)

Dave: Girls came here.

Don: You mean girl $_{\mathrm{CF}}$-girls.

Dave: You bet.

c. Jason: Buffy has turned into a dog.

Mary: Can I hope this is just a matter of slang usage, and Buffy has merely become somewhat unattractive?

Jason: No, she's a REAL dog. Four legs, tail, covered with fur, a $\operatorname{dog}_{\text {CF-dog. (adapted from Whitton (2006): } 28 \text { ) }}$ 
The drink $\mathbf{k}_{\mathrm{CF}}$-drink in (12a) refers to a drink category itself, which is marked by the outer box in Figure 3, in the situation where the category membership is at issue, meaning 'a genuine (real or actual) drink'. Similarly, the girl CF- girls in (12b) refer to a girl category itself, meaning 'any real girls', and the $\operatorname{dog}_{\mathrm{CF}}$-dog in (12c) refers to a dog category itself, meaning 'a genuine dog'.

In the mean time, the contrastive focus on the CF-reduplications presupposes an alternative question in the previous discourse as shown in (13).

$$
\begin{aligned}
& \text { a. } \quad \text { Do you want a lemonade prop or a real drink?\} } \\
& \text { Jason: A drink } \mathbf{C F}_{\mathrm{CF}} \text {-drink, silly! } \\
& \text { b. } \quad\left\{\text { Do you know whether they are actual girls or boys? }{ }^{8}\right\} \\
& \text { Don: You mean girl } \text { CF- }_{\text {girls? }} \\
& \text { c. } \quad \text { Is she a genuine dog or an unattractive person?\} } \\
& \text { Jason: She's a REAL dog. Four legs, tail, covered with fur, a } \\
& \operatorname{dog}_{\mathrm{CF}}-\mathrm{dog} \text {. }
\end{aligned}
$$

The contrastive focus on the $\mathbf{d r i n}_{\mathrm{CF}}$-drink in (13a) exhaustively selects the denotation of the CF-reduplications, a 'real drink' out of the presupposed disjuncts, real drink or lemonade prop. Likewise, the contrastive focus on the girl $_{\mathrm{CF}}$-girls in (13b) selects 'actual girls' and excludes the other disjunct 'boys'. The contrastive focus effects are true of the $\mathbf{d o g}_{\mathrm{CF}}-\mathrm{dog}$ in (13c), implying that She is no other dog than a genuine dog.

In addition, some other CF-reduplications refer to either of the two categories involving a lexeme, which can be termed 'Homonymous CF-reduplications', as shown in (14).

(14) a. Son: I want a bat for my birthday.

Dad: Aren't you afraid it will bite you?

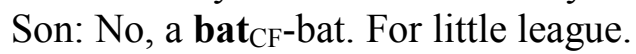

Dad: Aluminum bat?

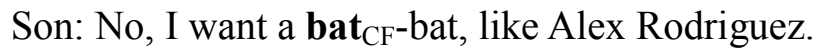

b. Son: I want a bat for my birthday.

Dad: A baseball bat?

Son: No, a bat ${ }_{\mathrm{CF}}$-bat. With wings.

Dad: A plain old one?

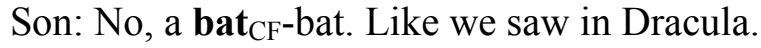

(adapted from Whitton 2006: 32)

8 Another possible alternative question can be \{Do you know whether they are actual girls or women? $\}$, when actual girls are contrasted with women like female teachers that have taught at that high school in the discourse. 
The first 'bat ${ }_{\mathrm{CF}}$-bat's in (14) refer to either of the categories ('a baseball bat' category or 'a flying mammal' category) involving the base word 'bat'. The semantic ambiguity stems from the existence of two separate categories in the extension of the lexeme 'BAT', as shown in Figure 4.

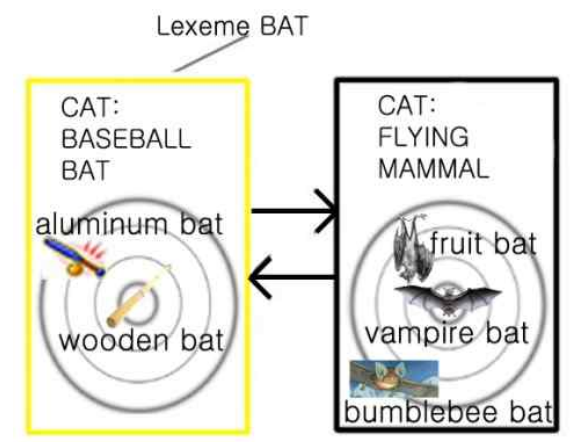

Figure 4 Prototype Structure of a 'bat' lexeme

In Figure 4, there are two separate categories in the lexical concept of the lexeme 'bat'. Unlike the prototype category of a 'drink' in Figure 3, this category has no outer box around it. Also, it has no complementary attribute that distinguishes between the 'baseball bat' category and the 'flying mammal' category. Like that in Figure 3, the solid line between the lexeme and the 'baseball category' indicates that the category is a default category, so that most English dictionaries place the former denotation above the latter denotation. ${ }^{9}$ Thus the ' $\mathbf{b a t}_{\mathrm{CF}}$-bat' has a denotation of 'a baseball bat' by default. As the bidirectional arrows indicate, the default denotation can undergo a transition to the other category by means of contrastive focus effects, when the default category is given in the context. The contrastive focus on the first ' $\mathbf{b a t}_{\mathrm{CF}}$-bat's indicate that the CF-reduplication is a response to each alternative question that forms with the disjuncts (a baseball bat or a flying mammal) in the previous discourse, as in (15).

(15) a. Dad: Aren't you afraid it will bite you?

\{Is it a flying mammal that you really want? or a baseball bat?\} Son: A bat $_{\mathrm{CF}}$-bat. For little league.

b. Dad: A baseball bat? \{Is it a baseball bat that you really want? or a flying mammal?\} Son: A bat $_{\mathrm{CF}}$-bat. With wings.

\footnotetext{
9 Collins Cobuild on CD-ROM (Lingea Lexicon, 2002, ver. 4.02), for instance, has the following lexical entry for the lexeme 'bat'.

1. A bat is a specially shaped piece of wood that is used for hitting the ball in baseball, soft ball, cricket, rounders, or table tennis.

2. A bat is a small flying animal that looks like a mouse with wings made of skin.
} 
The contrastive foci on CF-reduplications exhaustively select one of their denotations out of the two disjuncts given in the context in the way that the bat $_{\mathrm{CF}^{-}}$ bat in (15a) selects a 'baseball bat' and excludes the other while the one in (15b) selects a 'flying mammal' with the exclusion of 'baseball bat'. Once the denotation of the first 'bat ${ }_{\mathrm{CF}}$-bat's in (14) is disambiguated, the second 'bat CFbat's further denote a 'wooden bat' in (a), a 'vampire bat' ${ }^{10}$ in (b), respectively as the exemplar that matches the prototype of each category, as in Figure 4 above.

\section{Formal Aspects of Denotation of CF-reduplications}

So far, we have seen that CF-reduplications refer to each of the three different levels of a category: the prototype of a category, the subcategories in a category, and the category itself. A category is defined here as a collection of the mappings between sets. In that sense, the category of a base word in CF-reduplications is a collection of identity mappings between sets, which means the elements in the codomain are the same as those in the domain of the mapping, implying that a set of entities or properties (Set (X)) is equal to a category of entities or properties. Let us take the drink $\mathbf{K}_{\mathrm{CF}}$-drink as an example. The category of the base word 'drink' is equal to the set of 'drink' properties, which is composed of the immediately relevant alternative drinks in a situation where speakers participate. Returning to the prototype structure of a 'drink' category in Figure 3, the immediately relevant alternatives in the alcoholic subcategory are 'vodka', 'beer', 'gin' and 'wine' and those in the nonalcoholic subcategory are 'punch', 'coke', 'water' and 'iced tea'. These are the most relevant alternatives as they are most accessible by speakers with least effort in that situation. Now, the Set (X) will be represented as $\max (X)$ (c.f. Holliday 2010) with the formalization in (16).

$$
\begin{aligned}
& \max (\mathrm{X})=\left\{\mathrm{X}_{i} \in \mathrm{D}_{<\mathrm{e}, \triangleright} \mid \mathrm{X}_{j} \in \mathrm{D}_{<\mathrm{e}, \mathrm{t}\rangle}, \forall \mathrm{X}_{j} \leq \mathrm{X}_{i}\right\} \text {, where } \mathrm{D}_{<\mathrm{e}, \mathrm{t}} \text { is a } \\
& \text { nonempty set of properties, } \leq \text { is a relevance preordering, i.e. 'at } \\
& \text { least as relevant as'. }
\end{aligned}
$$

The CF-reduplications refer to either the element that best matches the prototype in $\max (\mathrm{X})$ or the subsets in $\max (\mathrm{X})$ or the $\max (\mathrm{X})$ itself. The CF-marked modifier plays a key role in determing the denotations of CF-reduplications in a unique

\footnotetext{
10 People have an image of bats as a dark and fearsome creature. Naturally, the vampire bat takes the place of prototype. It thirsts for blood and can drain a grown man dry in folk beliefs. The dad's initial response and son's denial in (14b) serves as a prop to eliminate artifact bats and then the dad and son's second round establishes a vampire bat as the real prototype bat $_{\mathrm{CF}}$-bat, contrasted with plain old ones.
} 
way at each level. Starting off with one instance of the CF-reduplications referring to the prototype in $\max \left(\right.$ Drink), drink $_{\mathrm{CF}}$-drink, as shown in (3a) above and repeated in (17),
a. Mary: Would you like a wine?
Jason: No, a drink $\mathrm{CF}_{\mathrm{CF}}$-drink. I'll have some vodka.
b. Mary: Would you like a coke?
Jason: No, a drink $\mathbf{C F}_{\mathrm{CF}}$-drink. I'll have some water.

the CF-marked modifier ( $\mathbf{d r i n k}_{\mathrm{CF}^{-}}$) of type $\langle<s,<e, t>>,<e, t>>$ receives the intension of the $\max$ (Drink) of type $\langle s,\langle e, t>>$ as an input, in which a possible world (or situation) is assigned to at least one element or one set of entities in max(Drink), which best matches the prototype of a category, as shown in (18).

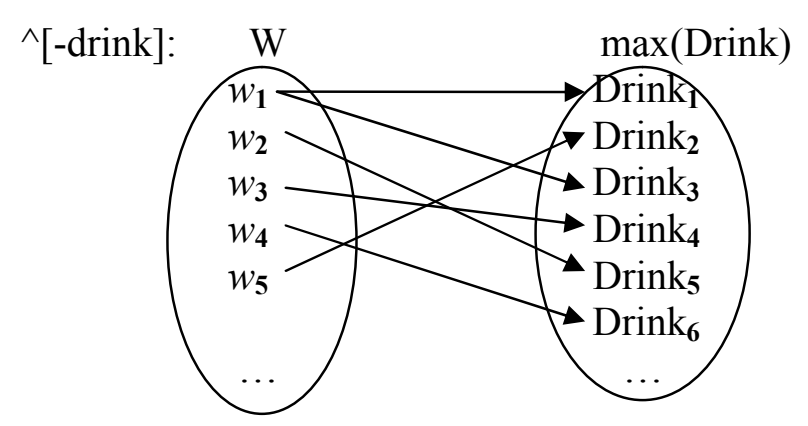

The intension of the base word in (18) involves an injective function that assigns at least an element of $\max$ (Drink) as a value to each possible world in such a way that it produces Drink (say, vodka) or Drink 3 (say, martini) at $w_{1}$, where a speaker is ordering an alcoholic drink at a bar, as in (17a), Drink 4 (say, coke) at $w_{3}$, where a speaker is ordering a nonalcoholic drink at a fast food restaurant, or Drink $\mathbf{6}_{\mathbf{6}}$ (say, water) at $w_{4}$, where a speaker is at the wheel of a car, as in (17b). Note that the value $\left(\mathrm{D}_{i}\right)$ of the intension of the base at $w_{i}$ is the set of entities in $\max$ (Drink) that best matches the prototype between speakers. With a similiarity preordering relation $\left(<_{\mathrm{p}}\right)$, the value is formalized as 'more similar to the prototype that any other elements are', as in (19).

$$
\begin{aligned}
& \mathbf{X}_{\mathrm{CF}^{-}}\left(w_{i}\right)=\lambda \mathrm{x}\left[\mathrm{X}_{i} \in \max (\mathrm{X}): \mathrm{X}_{i}<_{\mathrm{p}} \forall \mathrm{X}_{j} \in \max (\mathrm{X})\right] \text {, where }<_{\mathrm{p}} \text { is a } \\
& \text { similarity preordering over } \max (\mathrm{X}) \text {, that is, } \mathrm{A}<_{\mathrm{p}} \mathrm{B} \text { means " } \mathrm{A} \text { is } \\
& \text { more similar to the prototype than } \mathrm{B} \text { is". }
\end{aligned}
$$

With the intensional base word as an input, the CF-marked modifier $\mathbf{d r i n}_{\mathrm{CF}^{-}}$ yields the CF-reduplication of type $<e, t>$ as an output by taking a certain possible 
world as an argument and producing at least one element that is more similar to the prototype than any others are, as summarized in (20).

\section{Intensionalization of the base word}

$$
\begin{gathered}
\wedge\left[\left[-\mathrm{X}_{\mathrm{BASE}}\right]\right] \text { of }<s,<e, t>>=\lambda w\left[\lambda \mathrm{x}\left[\mathrm{X}_{i}(\mathrm{x}) \& \mathrm{X}_{i}<_{\mathrm{p}} \forall \mathrm{X}_{j} \text { at } w\right],\right. \\
\text { where } \mathrm{X}_{i,} \mathrm{X}_{j} \in \max (\mathrm{X}) .
\end{gathered}
$$

2. Denotation of the CF-modifier

$$
\left[\left[\mathrm{X}_{\mathrm{CF}^{-}}\right]\right] \text {of }\left\langle<s,<e, t>>,<e, t>>=\lambda \mathrm{A}_{<<\mathrm{s},<\mathrm{e}, \mathrm{t}>}[\lambda \mathrm{x}[\mathrm{A}(\mathrm{x})]]\right.
$$

3. Denotation of the CF-reduplication

$$
\left[\left[\mathrm{X}_{\mathbf{C F}}-\mathrm{X}\right]\right] \text { of }<e, t>=\left[\lambda \mathrm{x}\left[\mathrm{X}_{i}(\mathrm{x}) \& \mathrm{X}_{i}<_{\mathrm{p}} \forall \mathrm{X}_{j} \text { at } \mathrm{w}_{i}\right]\right]
$$

The drink $\mathbf{k}_{\mathrm{CF}}$-drink in (17a) undergoes that computational process to produce a denotation of 'vodka', as illustrated in (21).

$$
\begin{aligned}
\text { 1. } \left.\wedge^{\wedge}[-\operatorname{drink}]\right] & =\lambda w\left[\lambda \mathrm{x}\left[\operatorname{Drink}_{i}(\mathrm{x}) \& \operatorname{Drink}_{i}<_{\mathrm{p}} \forall \operatorname{Drink}_{j} \text { at } w\right]\right], \\
& \text { where } \operatorname{Drink}_{i} \operatorname{Drink}_{j} \in \max (\operatorname{Drink}) .
\end{aligned}
$$

2. $\left[\left[\operatorname{drink}_{\mathrm{CF}^{-}}\right]\right]=\lambda \mathrm{A}_{<<\mathrm{s},<\mathrm{e}, \triangleright>}[\lambda \mathrm{x}[\mathrm{A}(\mathrm{x})]]\left(\lambda w\left[\lambda \mathrm{x}\left[\operatorname{Drink}_{i}(\mathrm{x}) \& \operatorname{Drink}_{i}<_{\mathrm{p}}\right.\right.\right.$ $\forall \operatorname{Drink}_{j}$ at $\left.\left.\left.w\right]\right]\right)$

$$
\begin{aligned}
& =\lambda \mathrm{x}\left[\lambda w\left[\lambda \mathrm{x}\left[\operatorname{Drink}_{i}(\mathrm{x}) \& \operatorname{Drink}_{i}<_{\mathrm{p}} \forall \operatorname{Drink}_{j} \text { at } w\right]\right]\right](\mathrm{x}) \\
& =\lambda w\left[\lambda \mathrm{x}\left[\operatorname{Drink}_{i}(\mathrm{x}) \& \operatorname{Drink}_{i}<_{\mathrm{p}} \forall \operatorname{Drink}_{j} \text { at } w\right]\right]\left(\mathrm{w}_{l}\right) \\
& =\lambda \mathrm{x}\left[\operatorname{Drink}_{i}(\mathrm{x}) \& \operatorname{Drink}_{i}<_{\mathrm{p}} \forall \operatorname{Drink}_{j} \text { at } \mathrm{w}_{l}\right]
\end{aligned}
$$

3. $\left[\left[\operatorname{drink}_{\mathbf{C F}}-\mathrm{drink}\right]\right]=\lambda \mathrm{x}\left[\operatorname{Drink}_{i}(\mathrm{x}) \& \operatorname{Drink}_{i}<_{\mathrm{p}} \forall \operatorname{Drink}_{j}\right.$ at $\mathrm{w}_{l}=$ vodka

$$
=\lambda x[\operatorname{vodka}(\mathrm{x})]
$$

The contrastive focus (CF) makes a truth-functional contribution to the proposition $\left(\mathrm{p}_{<\mathrm{s}, \mathrm{t}}\right)$ containing the denotation of CF-reduplications by excluding the closed set of alternative propositions $\left(\mathrm{A}_{<<\mathrm{s}, \mathrm{t}, \mathrm{t},}\right)$ that have substitutions of immediately relevant alternatives in $\max (\mathrm{X})$ in the place of the denotation of the CF-reduplications, which is formalized as in (22).

$$
[[\mathrm{CF}]]\left(\mathrm{A}_{<<\mathrm{s}, \mathrm{t}, \mathrm{t}}\right) \mathrm{p}_{<\mathrm{s}, \mathrm{t}}(\mathrm{w})=1 \text { iff } \mathrm{p}(\mathrm{w}) \& \sim \mathrm{q}(\mathrm{w}), \forall \mathrm{q} \in \mathrm{A} \text {, where } \mathrm{A} \text { is }
$$
given in the discourse and takes the form of an alternative question.

The CF in (22) functions as an exhaustive operator to produce an exclusive implication that only the denotation of CF-reduplications is intended by the speaker. Returning to the drink $_{\mathrm{CF}}$-drink in (17a), the CF presupposes a set of alternative propositions in the form of an alternative question like "Would you like a wine or a vodka?" $(p \vee q)$. The alternative question implies that the speaker 
does not know which drink the addressee would like. However, the CF gets rid of the ignorance implicature by selecting one of the disjunct, "I would like a vodka." (p) and negating the other disjunct $(\sim q)$, thereby producing the implication that the speaker wants no other drink than a vodka.

Turning to the CF-reduplications referring to the subcategories in a category,

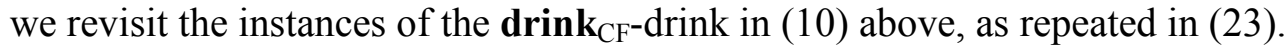

(23) Jason: I want a drink.

Mary: Here, have some coke.

Jason: No, I want a drink $\mathbf{C}_{\mathrm{CF}}$-drink. With alcohol.

Unlike the CF-marked modifier of CF-reduplications referring to the prototype of a category, that of the $\mathbf{d r i n}_{\mathrm{CF}}$-drink in (23) receives the intension of the base word that is a one-to-many function between a set of possible worlds and max(Drink) with two subcategories in it, as indicated by dotted circles in (24).

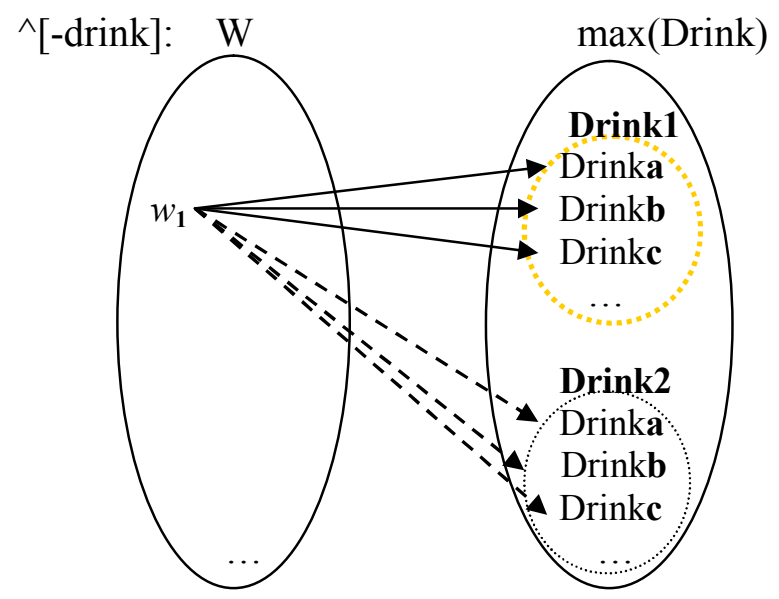

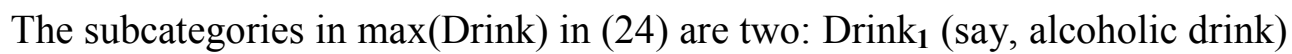
and Drink $_{2}$ (say, nonalcoholic drink). The alcoholic drink is a subcategory of the category 'drink' since all the elements of the former form a subset of those of the latter and all the mappings between the elements of the former are a subset of those between the elements of the latter. The nonalcoholic drink is also a subset of the category 'drink' for the same reason. Then, the CF-marked modifier drink $\mathbf{C F}_{\mathrm{CF}}$ produces the either-or denotations $\left(\operatorname{Drink}_{i}(\mathrm{x}) \vee \operatorname{Drink}_{j}(\mathrm{x})\right.$ ) of the CFreduplication of type $<e, t>$ by taking a certain possible world $\left(w_{1}\right)$ as an argument, as in (25).

$$
\begin{aligned}
& \text { 1. } \wedge^{\wedge}[[-\operatorname{drink}]]=\lambda w\left[\lambda \mathrm{x}\left[\operatorname{Drink}_{l}(\mathrm{x}) \vee \operatorname{Drink}_{2}(\mathrm{x}) \text { at } w\right]\right] \\
& \text { where } \forall \mathrm{x}\left[\operatorname{Drink}_{l}(\mathrm{x}) \rightarrow \sim \operatorname{Drink}_{2}(\mathrm{x}) \& \sim \operatorname{Drink}_{l}(\mathrm{x}) \rightarrow \operatorname{Drink}_{2}(\mathrm{x})\right],
\end{aligned}
$$




\section{2. $\left[\left[\operatorname{drink}_{\mathbf{C F}^{-}}\right]\right]=\lambda \mathrm{A}_{<<\mathrm{s},<e, \mathrm{p}>}[\lambda \times[\mathrm{A}(\mathrm{x})]]\left(\lambda w\left[\lambda \times\left[\operatorname{Drink}_{l}(\mathrm{x}) \vee \operatorname{Drink}_{2}(\mathrm{x})\right.\right.\right.$ at $\left.\left.\left.w\right]\right]\right)$ $=\lambda \mathrm{x}\left[\lambda w\left[\lambda \mathrm{x}\left[\operatorname{Drink}_{1}(\mathrm{x}) \vee \operatorname{Drink}_{2}(\mathrm{x})\right.\right.\right.$ at $\left.\left.\left.w\right]\right]\right](\mathrm{x})$$$
=\lambda w\left[\lambda \times\left[\operatorname{Drink}_{1}(\mathrm{x}) \vee \operatorname{Drink}_{2}(\mathrm{x}) \text { at } w\right]\right]\left(w_{1}\right)
$$ \\ 3. $\left[\left[\mathbf{d r i n k}_{\mathbf{C F}}-\mathrm{drink}\right]\right]=\lambda \mathbf{x}\left[\operatorname{Drink}_{l}(\mathrm{x}) \vee \operatorname{Drink}_{2}(\mathrm{x})\right.$ at $\left.w\right]$}

The contrastive focus (CF) serves to disambiguate either-or denotations ( $p$ or $q$ ) by excluding an alternative proposition $(\sim q)$ and selecting the other alternative $(p)$. Hence the drink $_{\mathrm{CF}}$-drink in (23) is construed as 'an alcoholic drink' with the focus effect ( $(p$ or $q) \& \sim q \rightarrow p)$.

Lastly, the CF-reduplications denote any members of the set in a situation where the membership is at issue, as in (12a) above and repeated in (26).

(26) Mary: (handing him the lemonade prop) Here!

Jason: A drink $\mathbf{C F}_{\mathrm{CF}}$-drink, silly!

The CF-marked modifier in (26) receives the intension of the base word that assings any elements of the category as a value to a possible world, as in (27), and produces the denotation of the CF-reduplication (max (Drink) itself by applying the function to a certain possible world (say, $w_{1}$ ), as in (28), with contrastive focus effects on the disjunction presupposed in the discourse, as indicated in (29).

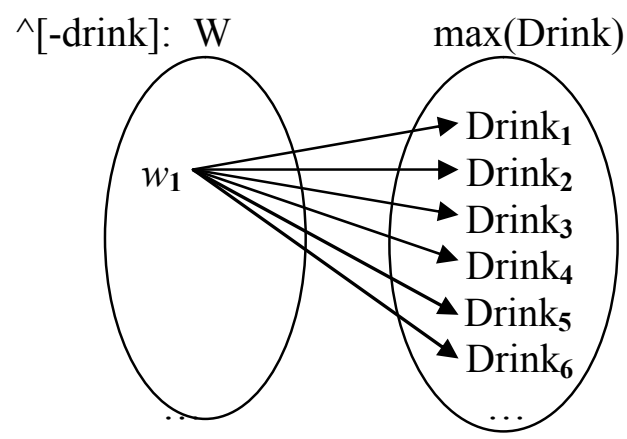

(28) $\quad$ 1.^$^{\wedge}[[-$ drink $]]=\lambda w\left[\lambda \mathrm{x}\left[\operatorname{Drink}_{i}(\mathrm{x})\right.\right.$ at $\left.\left.w\right]\right]$ where $\operatorname{Drink}_{i} \in \max (\operatorname{Drink})$.

2. $\left[\left[\operatorname{drink}_{\mathbf{C F}^{-}}\right]\right]=\lambda \mathrm{A}_{<<\mathrm{s},<\mathrm{e}, \mathrm{t}>>}[\lambda \mathrm{x}[\mathrm{A}(\mathrm{x})]]\left(\lambda w\left[\lambda \mathrm{x}\left[\operatorname{Drink}_{i}(\mathrm{x})\right.\right.\right.$ at $\left.\left.\left.w\right]\right]\right)$

$$
\begin{aligned}
& =\lambda \mathrm{x}\left[\lambda w\left[\lambda \mathrm{x}\left[\operatorname{Drink}_{i}(\mathrm{x}) \text { at } w\right]\right]\right](\mathrm{x}) \\
& =\lambda w\left[\lambda \mathrm{x}\left[\operatorname{Drink}_{i}(\mathrm{x}) \text { at } w\right]\right]\left(w_{1}\right)
\end{aligned}
$$

(29) 1. p or q: \{Do you want a lemonade prop or a genuine drink?\}

2. $\sim \mathrm{p}: \sim($ I want a lemonade prop)

3. $\therefore$ q: (I want a genuine drink) $\Rightarrow$ I want no other drink than a genuine drink. 


\section{Conclusion}

Up to now, we have seen how to interpret CF-reduplications in English ${ }^{11}$, based on a prototype category, dynamic prototypes and contrastive focus semantics. We proposed three different levels of a category as possible references of CFreduplications. One has a denotation that best matches the prototype of a category; another has a denotation that refers to the subcategories in a category; the third has a denotation that refers to a category itself. The CF-marked modifier ([[ $\left.\left.\left.\mathbf{X}_{\mathrm{CF}}{ }^{-}\right]\right]\right)$serves as a key to computing the denotations of CF-reduplications by receiving the intension of the base word $\left({ }^{\wedge}\left[\left[\mathrm{X}_{\mathrm{BASE}}\right]\right]\right)$ of type $\langle<s,\langle e, t>>,\langle e, t>>$ and assigning a prototypical element or any elements in either of the available complementary subcategories or any elements in a genuine (or real) category. This successfully gives an account of the contingently determined denotations of CF-reduplications, according to situations which speakers are in. Meanwhile, the contrastive focus serves to disambiguate the denotations of CF-reduplications by means of disjunction elimination $((p$ or $q) \& \sim q \rightarrow p)$ ) and also to produce the exclusive implication that the denotation of CF-reduplications is the only property or individual intended by the speakers. The contrastive focus effects seem to be similar to those of Whitton 2006 at first sight in the sense that it distinguishes between two or more possible interpretations and selects one over the others as an intended meaning. But the contrastive focus in our system disambiguates denotations of CF-reduplications by means of a logical inference rule whereas that in Whitton 2006 effects the intended and the rejected construals with a large number of ad-hoc dimensions and inconsistent scales. After all, CF-reduplications semantically have dynamically changing denotations and pragmatically facilitate the communication between speakers with contrastive focus effects.

\footnotetext{
11 The CF-reduplication phenomenon is also found in French like the following: une femme femme (a stylish woman); café café (strong-flavored coffee); le rouge rouge (red red); un chouchou (valuable (or cute) person or thing)); crayon crayon (a pencil that needs cutting); pomme pomme (apple as a fruit; pomme 'apple' in French is similar in form to 'potato' (pomme de terre). In Korean and Japanese, some affixes meaning 'true,' not reduplication, are employed to denote prototypes, e.g. cham-say 'sparrow' comes from cham 'true'-say 'bird.' Hohenhous (2004) put forward examples of CF-reduplications in other languages as below.

1. Italian: neri neri (really black, very darkjet black), caffe cqffe (true coffee)

2. Spanish: mina mina, or cuidad cuidad.

3. German: Film-Film (feature films as opposed to documentaries)
} 


\section{References}

Dray, Nancy. 1987. Doubles and Modifiers in English. Unpublished M.A. thesis, University of Chicago.

Ghomeshi, Jila, Ray Jackendoff, Nicole Rosen \& Russel, Kevin. 2004. Contrastive Focus Reduplication in English (the salad-salad paper). Natural Language and Linguistic Theory 22. 307-357.

Harel, David. 1987. Statecharts. A Visual Formalism for Complex Systems. Science of Computer Programming 8: 231-274.

Hohenhous, Peter. 2004. Identical Constituent Compounding - a Corpus-based Study. Folia Linguistica XXXVIII/3-4: 297-331.

Horn, Laurence R. 1993. Economy and Redundancy in a Dualistic Model of Natural Language. SKY: The Linguistic Association of Finland.

Holliday, Wesley H. 2010. Epistemic Logic and Relevant Alternatives. In M. Slavkovik, ed., Proceedings of the $15^{\text {th }}$ Student Session of the European Summer School in Logic, Language, and Information : 4-16.

Lee, Chungmin. 2010. Contrastive Topic and/or Contrastive Focus. Bill McClure (ed), Japanese/Korean Linguistics 12. CSLI, Stanford.

Taylor, John R. 1989. Linguistic Categorization: Prototypes in Linguistic Theory. Oxford, Great Britain: Clarendon Press.

Whitton, Laura. 2006. The Semantics of Contrastive Focus Reduplication in English: Does the Construction Mark Prototype-Prototype? Unpublished manuscript, CA.

Myounghyoun Song

Department of English Language \&

Literature

Seoul National University

1 Gwanangno Seoul 151-742, Korea

s720four@snu.ac.kr
Chungmin Lee

150-dong for Professors Emeriti

(Office 308)

Seoul National University

1 Gwanangno Seoul 151-742, Korea

clee@snu.ac.kr 